\title{
Convergence of splitting algorithms for the sum of two accretive operators with applications
}

\author{
Xiaolong Qin', Sun Young Cho² and Lin Wang ${ }^{3 *}$
}

\section{"Correspondence:}

w164mail@aliyun.com

${ }^{3}$ College of Statistics and

Mathematics, Yunnan University of

Finance and Economics, Kunming,

China

Full list of author information is

available at the end of the article

\begin{abstract}
We study a splitting algorithm for problems involving the sum of two accretive operators. We prove the strong convergence of the algorithm. Applications to variational inequality, fixed point, equilibrium, and minimization problems are provided.

Keywords: accretive operator; fixed point; nonexpansive mapping; resolvent; zero point
\end{abstract}

\section{Introduction}

Many important real world problems have reformulations which require finding zero points of some nonlinear operators, for instance, evolution equations, complementarity problems, mini-max problems, variational inequalities and optimization problems; see [111] and the references therein. It is well known that minimizing a convex function $f$ can be reduced to finding zero points of the subdifferential mapping $\partial f$. Forward-backward splitting algorithms were proposed by Lions and Mercier [12], by Passty [13], and, in a dual form for convex programming, by Han and Lou [14]. The algorithms, which provide a range of approaches to solving large-scale optimization problems and variational inequalities, have recently received much attention due to the fact that many nonlinear problems arising in applied areas such as image recovery, signal processing, and machine learning are mathematically modeled as a nonlinear operator equation, and this operator is decomposed as the sum of two nonlinear operators. This paper concerns a forwardbackward splitting algorithm with computational errors designed to find zeros of the sum of two accretive operators $A$ and $B$.

The paper is organized in the following way. In Section 2, we present the preliminaries that are needed in our work. In Section 3, we present a splitting algorithm for finding zeros of the sum of two accretive operators $A$ and $B$. Convergence analysis of the algorithms is investigated. In Section 4, applications of our main results are provided.

\section{Preliminaries}

Let $E$ be a real Banach space with the dual $E^{*}$. Given a continuous strictly increasing function $\varphi: R^{+} \rightarrow R^{+}$, where $R^{+}$denotes the set of nonnegative real numbers, such that $\varphi(0)=0$ and $\lim _{r \rightarrow \infty} \varphi(r)=\infty$, we associate with it a (possibly multivalued) generalized

(c) 2014 Qin et al.; licensee Springer. This is an Open Access article distributed under the terms of the Creative Commons Attribution License (http://creativecommons.org/licenses/by/2.0), which permits unrestricted use, distribution, and reproduction in any medium, provided the original work is properly cited. 
duality map $\mathfrak{J}_{\varphi}: E \rightarrow 2^{E^{*}}$, defined as $\mathfrak{J}_{\varphi}(x)=\left\{x^{*} \in E^{*}: x^{*}(x)=\|x\| \varphi(\|x\|),\left\|x^{*}\right\|=\varphi(\|x\|)\right\}$, $\forall x \in E$. In this paper, we use the generalized duality map associated with the gauge function $\varphi(t)=t^{q-1}$ for $q>1$. Let $\rho_{E}:[0, \infty) \rightarrow[0, \infty)$ be the modulus of smoothness of $E$ by $\rho_{E}(t)=\sup \left\{\frac{\|x+y\|-\|x-y\|}{2}-1, x \in U_{E},\|y\| \leq t\right\}$. A Banach space $E$ is said to be uniformly smooth if $\frac{\rho_{E}(t)}{t} \rightarrow 0$ as $t \rightarrow 0$. Let $q>1$. $E$ is said to be $q$-uniformly smooth if there exists a fixed constant $c>0$ such that $\rho_{E}(t) \leq c t^{q}$. The modulus of convexity of $E$ is the function $\delta_{E}(\epsilon):(0,2] \rightarrow[0,1]$ defined by $\delta_{E}(\epsilon)=\inf \left\{1-\frac{\|x+t\|}{2}:\|x\|=\|y\|=1,\|x-y\| \geq \epsilon\right\}$. Recall that $E$ is said to be uniformly convex if $\delta_{E}(\epsilon)>0$ for any $\epsilon \in(0,2]$. Let $E$ be a smooth Banach space, and let $C$ be a nonempty subset of $E$. Let $\operatorname{Proj}_{C}: E \rightarrow C$ be a retraction and $\mathfrak{J}$ be the normalized duality mapping on $E$. Then the following are equivalent [15]: (1) $\operatorname{Proj}_{C}$ is sunny and nonexpansive; (2) $\left\langle x-\operatorname{Proj}_{C} x, \mathfrak{J}\left(y-\operatorname{Proj}_{C} x\right)\right\rangle \leq 0, \forall x \in E, y \in C$.

Let $I$ denote the identity operator on $E$. An operator $A \subset E \times E$ with domain $D(A)=$ $\{z \in E: A z \neq \emptyset\}$ and range $R(A)=\bigcup\{A z: z \in D(A)\}$ is said to be accretive iff, for $t>0$ and $x, y \in D(A),\|x-y\| \leq\|x-y+t(u-v)\|, \forall u \in A x, v \in A y$. It follows from Kato [16] that $A$ is accretive iff, for $x, y \in D(A)$, there exists $\mathfrak{j}_{q}\left(x_{1}-x_{2}\right)$ such that $\left\langle u-v, \mathfrak{j}_{q}(x-y)\right\rangle \geq 0$. An accretive operator $A$ is said to be $m$-accretive iff $R(I+r A)=E$ for all $r>0$. In this paper, we use $A^{-1}(0)$ to denote the set of zeros of $A$. For an accretive operator $A$, we can define a nonexpansive single-valued mapping $J_{r}: R(I+r A) \rightarrow D(A)$ by $J_{r}=(I+r A)^{-1}$ for each $r>0$, which is called the resolvent of $A$. Recall that a single-valued operator $A: C \rightarrow E$ is said to be $\alpha$-inverse strongly accretive if there exists a constant $\alpha>0$ and some $\mathfrak{j}_{q}(x-y) \in \mathfrak{J}_{q}(x-y)$ such that $\left\langle A x-A y, \mathfrak{j}_{q}(x-y)\right\rangle \geq \alpha\|A x-A y\|^{q}, \forall x, y \in C$.

Let $T: C \rightarrow C$ be a mapping. Recall that $T$ is said to be $\kappa$-contractive iff there exists a constant $\kappa \in(0,1)$ such that $\|T x-T y\| \leq \kappa\|x, y\|, \forall x, y \in C$. $T$ is said to be nonexpansive iff $\kappa=1$. $T$ is said to be $\kappa$-strictly pseudocontractive iff there exists a constant $\kappa \in(0,1)$ such that

$$
\left\langle T x-T y, \mathrm{j}_{q}(x-y)\right\rangle \leq\|x-y\|^{q}-\kappa\|(x-T x)-(y-T y)\|^{q}, \quad \forall x, y \in C
$$

for some $\mathfrak{j}_{q}(x-y) \in \mathfrak{J}_{q}(x-y) . T$ is said to be pseudocontractive iff $\left\langle T x-T y, \mathfrak{j}_{q}(x-y)\right\rangle \leq$ $\|x-y\|^{q}, \forall x, y \in C$ for some $\mathfrak{j}_{q}(x-y) \in \mathfrak{J}_{q}(x-y)$.

In order to obtain our main results, we also need the following lemmas.

Lemma 2.1 [17] Let E be a real q-uniformly smooth Banach space. Then the following inequality holds: $\|x+y\|^{q} \leq\|x\|^{q}+q\left\langle y, \mathfrak{J}_{q}(x+y)\right\rangle$ and $\|x+y\|^{q} \leq\|x\|^{q}+q\left\langle y, \mathfrak{J}_{q}(x)\right\rangle+K_{q}\|y\|^{q}$, $\forall x, y \in E$, where $K_{q}$ is some fixed positive constant.

Lemma 2.2 [18] Let $E$ be a real Banach space, and let $C$ be a nonempty closed and convex subset of $E$. Let $A: C \rightarrow E$ be a single-valued operator, and let $B: E \rightarrow 2^{E}$ be an m-accretive operator. Then $F\left(J_{a}(I-a A)\right)=(A+B)^{-1}(0)$, where $J_{a}(I-a A)$ is the resolvent of $B$ for $a>0$.

Lemma 2.3 [19] Let $E$ be a real Banach space, and $A$ be an $m$-accretive operator. For $\lambda>0$, $\mu>0$, and $x \in E$, we have $J_{\lambda} x=J_{\mu}\left(\frac{\mu}{\lambda} x+\left(1-\frac{\mu}{\lambda}\right) J_{\lambda} x\right)$, where $J_{\lambda}=(I+\lambda A)^{-1}$ and $J_{\mu}=(I+\mu A)^{-1}$.

Lemma 2.4 [20] Let $\left\{a_{n}\right\}$ be a sequence of nonnegative real numbers such that $a_{n+1} \leq(1-$ $\left.t_{n}\right) a_{n}+b_{n}+c_{n}$, where $\left\{c_{n}\right\}$ is a sequence of nonnegative real numbers, $\left\{t_{n}\right\} \subset(0,1)$ and $\left\{b_{n}\right\}$ is a number sequence. Assume that $\sum_{n=0}^{\infty} t_{n}=\infty, \lim _{\sup _{n \rightarrow \infty}} \frac{b_{n}}{t_{n}} \leq 0$, and $\sum_{n=0}^{\infty} c_{n}<\infty$. Then $\lim _{n \rightarrow \infty} a_{n}=0$. 
Lemma 2.5 [21] Let $q>1$. Then the following inequality holds: $a b \leq \frac{a^{q}}{q}+\frac{q-1}{q} b^{\frac{q}{q-1}}$, for arbitrary positive real numbers $a$ and $b$.

Lemma 2.6 [22] Let $C$ be a nonempty closed convex subset of a real uniformly smooth Banach space E. Let $f: C \rightarrow C$ be a contractive mapping, and let $T: C \rightarrow C$ be a nonexpansive mapping. For each $t \in(0,1)$, let $x_{t}$ be the unique solution of the equation $x=$ $t f(x)+(1-t) T x$. Then $\left\{x_{t}\right\}$ converges strongly to a fixed point $\bar{x}=Q_{F(T)} f(\bar{x})$.

\section{Main results}

Theorem 3.1 Let E be a real q-uniformly smooth Banach space with the constant $K_{q}$. Let $B: E \rightarrow 2^{E}$ be an m-accretive operator such that $\overline{D(B)}$ is convex. Let $A: \overline{D(B)} \rightarrow E$ be an $\alpha$-inverse strongly accretive operator. Assume that $(A+B)^{-1}(0) \neq \emptyset$. Let $f: \overline{D(B)} \rightarrow \overline{D(B)}$ be a fixed $\kappa$-contraction. Let $\left\{r_{n}\right\},\left\{\alpha_{n}\right\},\left\{\beta_{n}\right\}$, and $\left\{\gamma_{n}\right\}$ be positive real number sequences, where $\left\{\alpha_{n}\right\},\left\{\beta_{n}\right\}$, and $\left\{\gamma_{n}\right\}$ are in $(0,1)$. Let $\left\{x_{n}\right\}$ be a sequence generated in the following iterative process:

$$
x_{0} \in C, \quad x_{n+1}=\alpha_{n} f\left(x_{n}\right)+\beta_{n} J_{r_{n}}\left(x_{n}-r_{n} A x_{n}+e_{n}\right)+\gamma_{n} f_{n}, \quad \forall n \geq 0,
$$

where $J_{r_{n}}=\left(I+r_{n} B\right)^{-1},\left\{e_{n}\right\}$ is a sequence in $E$, and $\left\{f_{n}\right\}$ is a bounded sequence in $\overline{D(B)}$. Assume that the sequences $\left\{\alpha_{n}\right\},\left\{\beta_{n}\right\},\left\{\gamma_{n}\right\},\left\{e_{n}\right\}$, and $\left\{r_{n}\right\}$ satisfy the following restrictions:

(1) $\alpha_{n}+\beta_{n}+\gamma_{n}=1$

(2) $\lim _{n \rightarrow \infty} \alpha_{n}=0, \sum_{n=0}^{\infty} \alpha_{n}=\infty$;

(3) $\sum_{n=1}^{\infty}\left|\beta_{n}-\beta_{n-1}\right|<\infty$;

(4) $\liminf _{n \rightarrow \infty} r_{n}>0, r_{n} \leq\left(\frac{q \alpha}{K_{q}}\right)^{\frac{1}{q-1}}, \sum_{n=1}^{\infty}\left|r_{n}-r_{n-1}\right|<\infty$;

(5) $\sum_{n=0}^{\infty}\left\|e_{n}\right\|<\infty, \sum_{n=0}^{\infty} \gamma_{n}<\infty$.

Then the sequence $\left\{x_{n}\right\}$ converges strongly to $x=\operatorname{Proj}_{(A+B)^{-1}(0)} f(x)$, where $\operatorname{Proj}_{(A+B)^{-1}(0)}$ is the unique sunny nonexpansive retraction of $C$ onto $(A+B)^{-1}(0)$.

Proof First, we show that $\left\{x_{n}\right\}$ is bounded. In view of Lemma 2.1, we find that

$$
\begin{aligned}
\| & \left(I-r_{n} A\right) x-\left(I-r_{n} A\right) y \|^{q} \\
& \leq\|x-y\|^{q}-q r_{n}\left\langle A x-A y, \mathfrak{J}_{q}(x-y)\right\rangle+K_{q} r_{n}^{q}\|A x-A y\|^{q} \\
& \leq\|x-y\|^{q}-q r_{n} \alpha\|A x-A y\|^{q}+K_{q} r_{n}^{q}\|A x-A y\|^{q} \\
& =\|x-y\|^{q}-\left(\alpha q-K_{q} r_{n}^{q-1}\right) r_{n}\|A x-A y\|^{q} .
\end{aligned}
$$

From restriction (4), we find that $I-r_{n} A$ is nonexpansive. Fixing $p \in(A+B)^{-1}(0)$, we find from Lemma 2.2 that $p=J_{r_{n}}\left(x_{n}-r_{n} A x_{n}\right) p$. It follows from restriction (5) that

$$
\begin{aligned}
& \left\|x_{n+1}-p\right\| \\
& \leq \alpha_{n}\left\|f\left(x_{n}\right)-p\right\|+\beta_{n}\left\|J_{r_{n}}\left(x_{n}-r_{n} A x_{n}+e_{n}\right)-p\right\|+\gamma_{n}\left\|f_{n}-p\right\| \\
& \leq \alpha_{n} \kappa\left\|x_{n}-p\right\|+\alpha_{n}\|f(p)-p\| \\
& \quad+\beta_{n}\left\|\left(x_{n}-r_{n} A x_{n}+e_{n}\right)-\left(I-r_{n} A\right) p\right\|+\gamma_{n}\left\|f_{n}-p\right\| \\
& \leq \\
& \leq\left(1-\alpha_{n}(1-\kappa)\right)\left\|x_{n}-p\right\|+\alpha_{n}\|f(p)-p\|+\left\|e_{n}\right\|+\gamma_{n}\left\|f_{n}-p\right\|
\end{aligned}
$$




$$
\begin{aligned}
\leq & \max \left\{\left\|x_{n}-p\right\|, \frac{\|f(p)-p\|}{1-\kappa}\right\}+\left\|e_{n}\right\|+\gamma_{n}\left\|f_{n}-p\right\| \\
\leq & \max \left\{\left\|x_{n-1}-p\right\|, \frac{\|f(p)-p\|}{1-\kappa}\right\}+\left\|e_{n-1}\right\|+\left\|e_{n}\right\| \\
& +\gamma_{n-1}\left\|f_{n-1}-p\right\|+\gamma_{n}\left\|f_{n}-p\right\| \\
& \vdots \\
\leq & \max \left\{\left\|x_{0}-p\right\|, \frac{\|f(p)-p\|}{1-\kappa}\right\}+\sum_{i=0}^{n}\left\|e_{i}\right\|+\sum_{i=0}^{n} \gamma_{i} M \\
\leq & \max \left\{\left\|x_{0}-p\right\|, \frac{\|f(p)-p\|}{1-\kappa}\right\}+\sum_{i=0}^{\infty}\left\|e_{i}\right\|+\sum_{i=0}^{\infty} \gamma_{i} M<\infty,
\end{aligned}
$$

where $M=\sup _{n \geq 0}\left\{\left\|f_{n}-p\right\|\right\}$. This shows that $\left\{x_{n}\right\}$ is bounded. Set $y_{n}=\left(I-r_{n} A\right) x_{n}+e_{n}$. It follows that

$$
\left\|y_{n-1}-y_{n}\right\| \leq\left\|x_{n}-x_{n-1}\right\|+\left|r_{n}-r_{n-1}\right|\left\|A x_{n-1}\right\|+\left\|e_{n}\right\|+\left\|e_{n-1}\right\| .
$$

Using Lemma 2.3, we find that

$$
\begin{aligned}
& \left\|J_{r_{n-1}} y_{n-1}-J_{r_{n}} y_{n}\right\| \\
& =\left\|J_{r_{n-1}}\left(\frac{r_{n-1}}{r_{n}} y_{n}+\left(1-\frac{r_{n-1}}{r_{n}}\right) J_{r_{n}} y_{n}\right)-J_{r_{n-1}} y_{n-1}\right\| \\
& \leq\left\|\frac{r_{n-1}}{r_{n}}\left(y_{n}-y_{n-1}\right)+\left(1-\frac{r_{n-1}}{r_{n}}\right)\left(J_{r_{n}} y_{n}-y_{n-1}\right)\right\| \\
& \leq\left\|y_{n}-y_{n-1}\right\|+\frac{\left|r_{n}-r_{n-1}\right|}{r_{n}}\left\|J_{r_{n}} y_{n}-y_{n}\right\| \\
& \leq\left\|x_{n}-x_{n-1}\right\|+\left|r_{n}-r_{n-1}\right|\left(\left\|A x_{n-1}\right\|+\frac{\left\|J_{r_{n}} y_{n}-y_{n}\right\|}{r_{n}}\right) \\
& \quad+\left\|e_{n}\right\|+\left\|e_{n-1}\right\| .
\end{aligned}
$$

On the other hand, we have

$$
\begin{aligned}
\left\|x_{n+1}-x_{n}\right\| \leq & \alpha_{n} \kappa\left\|x_{n}-x_{n-1}\right\|+\left|\alpha_{n}-\alpha_{n-1}\right|\left\|f\left(x_{n-1}\right)\right\| \\
& +\gamma_{n}\left\|f_{n}-f_{n-1}\right\|+\left|\gamma_{n}-\gamma_{n-1}\right|\left\|f_{n-1}\right\| \\
& +\beta_{n}\left\|J_{r_{n-1}} y_{n-1}-J_{r_{n}} y_{n}\right\|+\left|\beta_{n}-\beta_{n-1}\right|\left\|J_{r_{n-1}} y_{n-1}\right\| .
\end{aligned}
$$

Using (3.1) and (3.2), we find

$$
\begin{aligned}
\left\|x_{n+1}-x_{n}\right\| \leq & \left(1-\alpha_{n}(1-\kappa)\right)\left\|x_{n}-x_{n-1}\right\|+\left|\alpha_{n}-\alpha_{n-1}\right|\left\|f\left(x_{n-1}\right)\right\| \\
& +\gamma_{n}\left\|f_{n}-f_{n-1}\right\|+\left|\gamma_{n}-\gamma_{n-1}\right|\left\|f_{n-1}\right\| \\
& +\left|r_{n}-r_{n-1}\right|\left(\left\|A x_{n-1}\right\|+\frac{\left\|J_{r_{n}} y_{n}-y_{n}\right\|}{r_{n}}\right) \\
& +\left\|e_{n}\right\|+\left\|e_{n-1}\right\|+\left|\beta_{n}-\beta_{n-1}\right|\left\|J_{r_{n-1}} y_{n-1}\right\| .
\end{aligned}
$$


Using restrictions (3), (4), and (5), we obtain from Lemma 2.4 that

$$
\lim _{n \rightarrow \infty}\left\|x_{n+1}-x_{n}\right\|=0 .
$$

On the other hand, we have

$$
\left\|J_{r_{n}} y_{n}-x_{n}\right\| \leq \frac{\left\|x_{n+1}-x_{n}\right\|}{\beta_{n}}+\frac{\alpha_{n}}{\beta_{n}}\left\|x_{n}-f\left(x_{n}\right)\right\|+\frac{\gamma_{n}}{\beta_{n}}\left\|x_{n}-f_{n}\right\| .
$$

Using restrictions (2) and (5), we obtain from (3.3) that

$$
\lim _{n \rightarrow \infty}\left\|J_{r_{n}} y_{n}-x_{n}\right\|=0
$$

Since

$$
\begin{aligned}
\left\|J_{r_{n}}\left(x_{n}-r_{n} A x_{n}\right)-x_{n}\right\| & \leq\left\|J_{r_{n}}\left(x_{n}-r_{n} A x_{n}\right)-J_{r_{n}} y_{n}\right\|+\left\|J_{r_{n}} y_{n}-x_{n}\right\| \\
& \leq\left\|e_{n}\right\|+\left\|J_{r_{n}} y_{n}-x_{n}\right\|,
\end{aligned}
$$

we find from (3.4) and restriction (5) that

$$
\lim _{n \rightarrow \infty}\left\|J_{r_{n}}\left(x_{n}-r_{n} A x_{n}\right)-x_{n}\right\|=0 .
$$

Without loss of generality, let us assume that there exists a real number $r$ such that $r_{n} \geq$ $r>0$. Since $B$ is accretive, we have

$$
\left\langle\frac{x_{n}-J_{r}(I-r A) x_{n}}{r}-\frac{x_{n}-J_{r_{n}}\left(I-r_{n} A\right) x_{n}}{r_{n}}, \mathfrak{J}_{q}\left(J_{r}(I-r A) x_{n}-J_{r_{n}}\left(I-r_{n} A\right) x_{n}\right)\right\rangle \geq 0 .
$$

It follows that

$$
\begin{aligned}
& \left\|J_{r}(I-r A) x_{n}-J_{r_{n}}\left(I-r_{n} A\right) x_{n}\right\|^{q} \\
& \quad \leq \frac{r_{n}-r}{r_{n}}\left\langle x_{n}-J_{r_{n}}\left(I-r_{n} A\right) x_{n}, \mathfrak{J}_{q}\left(J_{r}(I-r A) x_{n}-J_{r_{n}}\left(I-r_{n} A\right) x_{n}\right)\right\rangle \\
& \quad \leq\left\|x_{n}-J_{r_{n}}\left(I-r_{n} A\right) x_{n}\right\|\left\|J_{r}(I-r A) x_{n}-J_{r_{n}}\left(I-r_{n} A\right) x_{n}\right\|^{q-1} .
\end{aligned}
$$

This implies from (3.5) that

$$
\lim _{n \rightarrow \infty}\left\|J_{r}\left(x_{n}-r A x_{n}\right)-x_{n}\right\|=0 .
$$

Since $J_{r}(I-r A)$ is nonexpansive and $f$ is contractive, we find that the mapping $t f+(1-$ $t) J_{r}(I-r A)$ is contractive. Let $x_{t}$ be the unique fixed point of the mapping $t f+(1-t) J_{r}(I-$ $r A)$, that is, $x_{t}=t f\left(x_{t}\right)+(1-t) J_{r}(I-r A) x_{t}, \forall t \in(0,1)$. Setting $x=\lim _{t \rightarrow 0} x_{t}$, we have $x=$ $\operatorname{Proj}_{(A+B)^{-1}(0)} f(x)$, where $\operatorname{Proj}_{(A+B)^{-1}(0)}$ is the unique sunny nonexpansive retraction from $C$ onto $(A+B)^{-1}(0)$.

Next, we show that

$$
\limsup _{n \rightarrow \infty}\left\{f(x)-x, \mathfrak{J}_{q}\left(x_{n}-x\right)\right\rangle \leq 0 .
$$


Since

$$
\begin{aligned}
\left\|x_{t}-x_{n}\right\|^{q} \leq & t\left\langle f\left(x_{t}\right)-x_{n}, \mathfrak{J}_{q}\left(x_{t}-x_{n}\right)\right\rangle \\
& +(1-t)\left\langle J_{r}(I-r A) x_{t}-x_{n}, \mathfrak{J}_{q}\left(x_{t}-x_{n}\right)\right\rangle \\
\leq & t\left\langle f\left(x_{t}\right)-x_{t}, \mathfrak{J}_{q}\left(x_{t}-x_{n}\right)\right\rangle+t\left\langle x_{t}-x_{n}, \mathfrak{J}_{q}\left(x_{t}-x_{n}\right)\right\rangle \\
& +(1-t)\left\langle J_{r}(I-r A) x_{t}-J_{r}(I-r A) x_{n}, \mathfrak{J}_{q}\left(x_{t}-x_{n}\right)\right\rangle \\
& +(1-t)\left\langle J_{r}(I-r A) x_{n}-x_{n}, \mathfrak{J}_{q}\left(x_{t}-x_{n}\right)\right\rangle \\
\leq & t\left\langle f\left(x_{t}\right)-x_{t}, \mathfrak{J}_{q}\left(x_{t}-x_{n}\right)\right\rangle+\left\|x_{t}-x_{n}\right\|^{q} \\
& +\left\|J_{r}(I-r A) x_{n}-x_{n}\right\|\left\|x_{t}-x_{n}\right\|^{q-1},
\end{aligned}
$$

we have

$$
\left\langle f\left(x_{t}\right)-x_{t}, \mathfrak{J}_{q}\left(x_{n}-x_{t}\right)\right\rangle \leq \frac{1}{t}\left\|J_{r}(I-r A) x_{n}-x_{n}\right\|\left\|x_{t}-x_{n}\right\|^{q-1} .
$$

Fix $t$ and let $n \rightarrow \infty$. It follows from (3.6) that

$$
\limsup _{n \rightarrow \infty}\left\langle f\left(x_{t}\right)-x_{t}, \mathfrak{J}_{q}\left(x_{n}-x_{t}\right)\right\rangle \leq 0
$$

Since the duality map $\mathfrak{J}_{q}$ is single-valued and strong-weak* uniformly continuous on bounded sets of a Banach space $E$ with a uniformly Gâteaux differentiable norm, one has

$$
\begin{aligned}
\left|\left\langle f\left(x_{t}\right)-x_{t}, \mathfrak{J}_{q}\left(x_{n}-x_{t}\right)\right\rangle-\left\langle f(x)-x, \mathfrak{J}_{q}\left(x_{n}-x\right)\right\rangle\right| & \\
= & \mid\left\langle f(x)-x, \mathfrak{J}_{q}\left(x_{n}-x\right)-\mathfrak{J}_{q}\left(x_{n}-x_{t}\right)\right\rangle \\
& +\left\langle f(x)-x-\left(f\left(x_{t}\right)-x_{t}\right), \mathfrak{J}_{q}\left(x_{n}-x_{t}\right)\right\rangle \mid \\
\leq & \left|\left\langle f(x)-x, \mathfrak{J}_{q}\left(x_{n}-x\right)-\mathfrak{J}_{q}\left(x_{n}-x_{t}\right)\right\rangle\right| \\
& +\left\|f(x)-x-\left(f\left(x_{t}\right)-x_{t}\right)\right\|\left\|x_{n}-x_{t}\right\|^{q-1} .
\end{aligned}
$$

Hence, $\forall \epsilon>0, \exists \delta>0$ such that $t \in(0, \delta)$, one has

$$
\left\langle f(x)-x, \mathfrak{J}_{q}\left(x_{n}-x\right)\right\rangle \leq\left\langle f\left(x_{t}\right)-x_{t}, \mathfrak{J}_{q}\left(x_{n}-x_{t}\right)\right\rangle+\epsilon \text {. }
$$

Using (3.7), we see that

$$
\limsup _{n \rightarrow \infty}\left\langle f(x)-x, \mathfrak{J}_{q}\left(x_{n}-\bar{x}\right)\right\rangle \leq 0 .
$$

Using Lemma 2.5, one has

$$
\begin{aligned}
\left\|x_{n+1}-x\right\|^{q} \leq & \alpha_{n}\left\langle f\left(x_{n}\right)-f(x), \mathfrak{J}_{q}\left(x_{n+1}-x\right)\right\rangle+\alpha_{n}\left\langle f(x)-x, \mathfrak{J}_{q}\left(x_{n+1}-\bar{x}\right)\right\rangle \\
& +\beta_{n}\left\|J_{r_{n}}\left(x_{n}-r_{n} A x_{n}+e_{n}\right)-x\right\|\left\|x_{n+1}-x\right\|^{q-1} \\
& +\gamma_{n}\left\|f_{n}-x\right\|\left\|x_{n+1}-x\right\|^{q-1} \\
\leq & \left(1-\alpha_{n}(1-\kappa)\right)\left\|x_{n}-x\right\|\left\|x_{n+1}-x\right\|^{q-1}
\end{aligned}
$$




$$
\begin{aligned}
& +\alpha_{n}\left\langle f(x)-x, \mathfrak{J}_{q}\left(x_{n+1}-x\right)\right\rangle+\left\|e_{n}\right\|\left\|x_{n+1}-x\right\|^{q-1} \\
& +\gamma_{n}\left\|f_{n}-x\right\|\left\|x_{n+1}-x\right\|^{q-1} \\
\leq & \left(1-\alpha_{n}(1-\kappa)\right)\left(\frac{1}{q}\left\|x_{n}-x\right\|^{q}+\frac{q-1}{q}\left\|x_{n+1}-x\right\|^{q}\right) \\
& +\alpha_{n}\left\langle f(x)-x, \mathfrak{J}_{q}\left(x_{n+1}-x\right)\right\rangle+\left\|e_{n}\right\|\left\|x_{n+1}-x\right\|^{q-1} \\
& +\gamma_{n}\left\|f_{n}-x\right\|\left\|x_{n+1}-x\right\|^{q-1} .
\end{aligned}
$$

It follows that

$$
\begin{aligned}
\left\|x_{n+1}-x\right\|^{q} \leq & \left(1-\alpha_{n}(1-\kappa)\right)\left\|x_{n}-x\right\|^{q} \\
& +q \alpha_{n}\left\langle f(x)-x, \mathfrak{J}_{q}\left(x_{n+1}-x\right)\right\rangle+q\left\|e_{n}\right\|\left\|x_{n+1}-x\right\|^{q-1} \\
& +q \gamma_{n}\left\|f_{n}-x\right\|\left\|x_{n+1}-x\right\|^{q-1} .
\end{aligned}
$$

Using restrictions (2) and (5), we see from (3.8) that $\left\{x_{n}\right\}$ converges strongly to $x$. This completes the proof.

Remark 3.2 The framework of the space in Theorem 3.1 can be applicable to $L_{p}$, where $p>1$.

Corollary 3.3 Let E be a real q-uniformly smooth Banach space with the constant $K_{q}$. Let $B: E \rightarrow 2^{E}$ be an m-accretive operator such that $\overline{D(B)}$ is convex. Assume that $B^{-1}(0) \neq \emptyset$. Let $f: \overline{D(B)} \rightarrow \overline{D(B)}$ be a fixed $\kappa$-contraction. Let $\left\{r_{n}\right\}$ and $\left\{\alpha_{n}\right\}$ be positive real number sequences, where $\left\{\alpha_{n}\right\}$ is in $(0,1)$. Let $\left\{x_{n}\right\}$ be a sequence generated in the following iterative process:

$$
x_{0} \in C, \quad x_{n+1}=\alpha_{n} f\left(x_{n}\right)+\left(1-\alpha_{n}\right) J_{r_{n}} x_{n}, \quad \forall n \geq 0,
$$

where $J_{r_{n}}=\left(I+r_{n} B\right)^{-1}$. Assume that the sequences $\left\{\alpha_{n}\right\}$ and $\left\{r_{n}\right\}$ satisfy the following restrictions:

(1) $\lim _{n \rightarrow \infty} \alpha_{n}=0, \sum_{n=0}^{\infty} \alpha_{n}=\infty$;

(2) $\sum_{n=1}^{\infty}\left|\alpha_{n}-\alpha_{n-1}\right|<\infty$;

(3) $\liminf _{n \rightarrow \infty} r_{n}>0, \sum_{n=1}^{\infty}\left|r_{n}-r_{n-1}\right|<\infty$.

Then the sequence $\left\{x_{n}\right\}$ converges strongly to $x=\operatorname{Proj}_{B^{-1}(0)} f(x)$, where $\operatorname{Proj}_{B^{-1}(0)}$ is the unique sunny nonexpansive retraction of $C$ onto $B^{-1}(0)$.

Corollary 3.4 Let E be a real q-uniformly smooth Banach space with the constant $K_{q}$, and let $C$ be a nonempty closed and convex subset of E. Let $f: C \rightarrow C$ be a fixed $\kappa$-contraction. Let $T: C \rightarrow C$ be an $\alpha$-strictly pseudocontractive mapping with a nonempty fixed point set. Let $\left\{r_{n}\right\},\left\{\alpha_{n}\right\},\left\{\beta_{n}\right\}$, and $\left\{\gamma_{n}\right\}$ be positive number sequences, where $\left\{\alpha_{n}\right\},\left\{\beta_{n}\right\}$, and $\left\{\gamma_{n}\right\}$ in $(0,1)$. Let $\left\{x_{n}\right\}$ be a sequence generated in the following process:

$$
x_{0} \in C, \quad x_{n+1}=\alpha_{n} f\left(x_{n}\right)+\beta_{n}\left(1-r_{n}\right) x_{n}+r_{n} \beta_{n} T x_{n}+\gamma_{n} f_{n}, \quad \forall n \geq 0,
$$

where $\left\{f_{n}\right\}$ is a bounded sequence in C. Assume that the sequences $\left\{\alpha_{n}\right\},\left\{\beta_{n}\right\},\left\{\gamma_{n}\right\}$, and $\left\{r_{n}\right\}$ satisfy the following restrictions: 
(1) $\alpha_{n}+\beta_{n}+\gamma_{n}=1$

(2) $\lim _{n \rightarrow \infty} \alpha_{n}=0, \sum_{n=0}^{\infty} \alpha_{n}=\infty$;

(3) $\sum_{n=1}^{\infty}\left|\beta_{n}-\beta_{n-1}\right|<\infty$;

(4) $\liminf _{n \rightarrow \infty} r_{n}>0, r_{n} \leq\left(\frac{q \alpha}{K_{q}}\right)^{\frac{1}{q-1}}, \sum_{n=1}^{\infty}\left|r_{n}-r_{n-1}\right|<\infty$;

(5) $\sum_{n=0}^{\infty} \gamma_{n}<\infty$.

Then the sequence $\left\{x_{n}\right\}$ converges strongly to $x=\operatorname{Proj}_{F(T)} f(x)$, where $\operatorname{Proj}_{F(T)}$ is the unique sunny nonexpansive retraction of $C$ onto $F(T)$.

Proof Putting $A=I-T$, we find that $A$ is $\alpha$-inverse strongly accretive and $F(T)=A^{-1}(0)$. Notice that

$$
\begin{aligned}
x_{n+1} & =\alpha_{n} f\left(x_{n}\right)+\beta_{n}\left(1-r_{n}\right) x_{n}+r_{n} \beta_{n} T x_{n}+\gamma_{n} f_{n} \\
& =\alpha_{n} f\left(x_{n}\right)+\beta_{n}\left(\left(1-r_{n}\right) x_{n}+r_{n} T x_{n}\right)+\gamma_{n} f_{n} \\
& =\alpha_{n} f\left(x_{n}\right)+\beta_{n}\left(x_{n}-r_{n}(I-T) x_{n}\right)+\gamma_{n} f_{n} \\
& =\alpha_{n} f\left(x_{n}\right)+\beta_{n}\left(x_{n}-r_{n} A x_{n}\right)+\gamma_{n} f_{n} .
\end{aligned}
$$

Using Theorem 3.1, we find the desired conclusion immediately.

\section{Applications}

In this section, we give some applications of our main results in the framework of Hilbert spaces.

From now on, we always assume that $C$ is a nonempty closed and convex subset of a real Hilbert space $H$ and $P_{C}$ stands for the metric projection from $H$ onto $C$. Let $A: C \rightarrow H$ be a monotone operator. Recall that the classical variational inequality is to find $x \in C$ such that

$$
\langle A x, y-x\rangle \geq 0, \quad \forall y \in C
$$

The solution set of the variational inequality is denoted by $\mathrm{VI}(C, A)$.

Let $i_{C}$ be a function defined by

$$
i_{C}(x)= \begin{cases}0, & x \in C, \\ \infty, & x \notin C .\end{cases}
$$

It is easy to see that $i_{C}$ is a proper lower and semicontinuous convex function on $H$, and the subdifferential $\partial i_{C}$ of $i_{C}$ is maximal monotone. Define the resolvent $J_{r}:=\left(I+r \partial i_{C}\right)^{-1}$ of the subdifferential operator $\partial i_{C}$. Letting $x=J_{r} y$, we find that

$$
\begin{aligned}
y \in x+r \partial i_{C} x & \Longleftrightarrow y \in x+r N_{C} x \\
& \Longleftrightarrow\langle y-x, v-x\rangle \leq 0, \quad \forall v \in C \\
& \Longleftrightarrow x=P_{C} y,
\end{aligned}
$$

where $N_{C} x:=\{e \in H:\langle e, v-x\rangle, \forall v \in C\}$.

Putting $B=\partial i_{C}$ in Theorem 3.1, we find that $J_{r_{n}}=P_{C}$. Hence, the following result can be obtained immediately. 
Theorem 4.1 Let $f: C \rightarrow C$ be a fixed $\kappa$-contraction. Let $A: C \rightarrow E$ be an $\alpha$-inverse strongly monotone operator with $\operatorname{VI}(C, A) \neq \emptyset$. Let $\left\{r_{n}\right\}$ be a positive number sequence. Let $\left\{\alpha_{n}\right\},\left\{\beta_{n}\right\}$, and $\left\{\gamma_{n}\right\}$ be real number sequences in $(0,1)$. Let $\left\{x_{n}\right\}$ be a sequence generated in the following iterative process:

$$
x_{0} \in C, \quad x_{n+1}=\alpha_{n} f\left(x_{n}\right)+\beta_{n} P_{C}\left(x_{n}-r_{n} A x_{n}+e_{n}\right)+\gamma_{n} f_{n}, \quad \forall n \geq 0,
$$

where $\left\{e_{n}\right\}$ is a sequence in $H$ and $\left\{f_{n}\right\}$ is a bounded sequence in $C$. Assume that the sequences $\left\{\alpha_{n}\right\},\left\{\beta_{n}\right\},\left\{\gamma_{n}\right\},\left\{e_{n}\right\}$, and $\left\{r_{n}\right\}$ satisfy the following restrictions:

(1) $\alpha_{n}+\beta_{n}+\gamma_{n}=1$

(2) $\lim _{n \rightarrow \infty} \alpha_{n}=0, \sum_{n=0}^{\infty} \alpha_{n}=\infty$;

(3) $\sum_{n=1}^{\infty}\left|\beta_{n}-\beta_{n-1}\right|<\infty$;

(4) $\liminf _{n \rightarrow \infty} r_{n}>0, r_{n} \leq 2 \alpha, \sum_{n=1}^{\infty}\left|r_{n}-r_{n-1}\right|<\infty$;

(5) $\sum_{n=0}^{\infty}\left\|e_{n}\right\|<\infty, \sum_{n=0}^{\infty} \gamma_{n}<\infty$.

Then the sequence $\left\{x_{n}\right\}$ converges strongly to $x=P_{\mathrm{VI}(C, A)} f(x)$, where $P_{\mathrm{VI}(C, A)}$ is the unique metric projection from $C$ onto $\mathrm{VI}(C, A)$.

Next, we consider the problem of finding a solution of a Ky Fan inequality [23], which is known as an equilibrium problem in the terminology of Blum and Oettli; see [24] and the references therein.

Let $F$ be a bifunction of $C \times C$ into $\mathbb{R}$, where $\mathbb{R}$ denotes the set of real numbers. Recall the following equilibrium problem:

$$
\text { Find } x \in C \text { such that } F(x, y) \geq 0, \quad \forall y \in C \text {. }
$$

The solution set of the problem is denoted by $\operatorname{EP}(F)$ in this section.

To study the equilibrium problem (4.2), we may assume that $F$ satisfies the following restrictions:

(A1) $F(x, x)=0$ for all $x \in C$;

(A2) $F$ is monotone, i.e., $F(x, y)+F(y, x) \leq 0$ for all $x, y \in C$;

(A3) for each $x, y, z \in C, \lim \sup _{t \downarrow 0} F(t z+(1-t) x, y) \leq F(x, y)$;

(A4) for each $x \in C, y \mapsto F(x, y)$ is convex and lower semicontinuous.

The following lemma can be found in [24].

Lemma 4.2 Let $F: C \times C \rightarrow \mathbb{R}$ be a bifunction satisfying (A1)-(A4). Then, for any $r>0$ and $x \in H$, there exists $z \in C$ such that $F(z, y)+\frac{1}{r}\langle y-z, z-x\rangle \geq 0, \forall y \in C$. Further, define

$$
T_{r} x=\left\{z \in C: F(z, y)+\frac{1}{r}\langle y-z, z-x\rangle \geq 0, \forall y \in C\right\}
$$

for all $r>0$ and $x \in H$. Then (1) $T_{r}$ is single-valued and firmly nonexpansive; (2) $F\left(T_{r}\right)=$ $\mathrm{EP}(F)$ is closed and convex.

Lemma 4.3 Let $F$ be a bifunction from $C \times C$ to $\mathbb{R}$ which satisfies (A1)-(A4), and let $A_{F}$ be a multivalued mapping of $H$ into itself defined by

$$
A_{F} \mathcal{X}= \begin{cases}\{z \in H: F(x, y) \geq\langle y-x, z\rangle, \forall y \in C\}, & x \in C, \\ \emptyset, & x \notin C .\end{cases}
$$


Then $A_{F}$ is a maximal monotone operator with the domain $D\left(A_{F}\right) \subset C, \operatorname{EP}(F)=A_{F}^{-1}(0)$, and $T_{r} x=\left(I+r A_{F}\right)^{-1} x, \forall x \in H, r>0$, where $T_{r}$ is defined as in (4.3).

Based on Lemmas 4.2 and 4.3, we find from Theorem 3.1 the following immediately.

Theorem 4.4 Let $F: C \times C \rightarrow \mathbb{R}$ be a bifunction satisfying (A1)-(A4) such that $\mathrm{EP}(F)$ is not empty. Let $f: C \rightarrow C$ be a fixed $\kappa$-contraction. Let $\left\{r_{n}\right\}$ be a positive number sequence. Let $\left\{\alpha_{n}\right\},\left\{\beta_{n}\right\}$, and $\left\{\gamma_{n}\right\}$ be real number sequences in $(0,1)$. Let $\left\{x_{n}\right\}$ be a sequence generated in the following iterative process:

$$
x_{0} \in C, \quad x_{n+1}=\alpha_{n} f\left(x_{n}\right)+\beta_{n} T_{r_{n}}\left(x_{n}-r_{n} A x_{n}+e_{n}\right)+\gamma_{n} f_{n}, \quad \forall n \geq 0,
$$

where $J_{r_{n}}=\left(I+r_{n} A_{F}\right)^{-1},\left\{e_{n}\right\}$ is a sequence in $H$ and $\left\{f_{n}\right\}$ is a bounded sequence in C. Assume that the sequences $\left\{\alpha_{n}\right\},\left\{\beta_{n}\right\},\left\{\gamma_{n}\right\},\left\{e_{n}\right\}$, and $\left\{r_{n}\right\}$ satisfy the following restrictions:

(1) $\alpha_{n}+\beta_{n}+\gamma_{n}=1$

(2) $\lim _{n \rightarrow \infty} \alpha_{n}=0, \sum_{n=0}^{\infty} \alpha_{n}=\infty$;

(3) $\sum_{n=1}^{\infty}\left|\beta_{n}-\beta_{n-1}\right|<\infty$;

(4) $\liminf _{n \rightarrow \infty} r_{n}>0, r_{n} \leq 2 \alpha, \sum_{n=1}^{\infty}\left|r_{n}-r_{n-1}\right|<\infty$;

(5) $\sum_{n=0}^{\infty}\left\|e_{n}\right\|<\infty, \sum_{n=0}^{\infty} \gamma_{n}<\infty$.

Then the sequence $\left\{x_{n}\right\}$ converges strongly to some point in $\mathrm{EP}(F)$.

For any matrix $D \in \mathfrak{R}^{m \times n}$, we denote its transpose by $D^{T}$ and its operator norm by $\|D\|=$ $\max _{x \in \Re^{n}:\|x\|=1}\|D x\|$.

Consider the inclusion problem [10] $0 \in A\left(x_{1}, x_{2}, y\right)+B\left(x_{1}, x_{2}, y\right)$, where $A\left(x_{1}, x_{2}, y\right)=$ $\left(D^{T} y, E^{T} y,-D x_{1}-E x_{2}\right), B\left(x_{1}, x_{2}, y\right)=T_{1} x_{1} \times T_{2} x_{2} \times\{b\}$ and $T_{1}$ and $T_{2}$ are maximal monotone mappings on $\Re^{n_{1}}$ and $\mathfrak{R}^{n_{2}}$, respectively, and $D \in \mathfrak{R}^{m \times n_{1}}, E \in \mathfrak{R}^{m \times n_{2}}, b \in \mathfrak{R}^{m}$. Then, $A$ and $B$ are maximal monotone and $A$ is Lipschitz continuous on $\Re^{m+n_{1}+n_{2}}$ with the constant

$$
\eta=\sqrt{\left\|D^{T}\right\|^{2}+\left\|E^{T}\right\|^{2}+\|D\|^{2}+\|E\|^{2}} .
$$

The special case where $T_{1}=\partial f_{1}, T_{2}=\partial f_{2}$ yields the following convex program:

$$
\left\{\begin{array}{l}
\text { minimize } f_{1}\left(x_{1}\right)+f_{2}\left(x_{2}\right) \\
\text { subject to } D x_{1}+E x_{2}=b,
\end{array}\right.
$$

where $f_{1}$ and $f_{2}$ are closed proper convex functions on, respectively, $\mathfrak{R}^{n_{1}}$ and $\mathfrak{R}^{n_{2}}$. The special case where $n_{1}=n_{2}, D=-E=I$ and $b=0$ yields the inclusion $0 \in T_{1} x+T x_{2}$.

Finally, we consider finding minimizers of proper lower semicontinuous convex functions.

For a proper lower semicontinuous convex function $h: H \rightarrow(-\infty, \infty]$, the subdifferential mapping $\partial h$ of $h$ is defined by

$$
\partial h(x)=\left\{x^{*} \in H: h(x)+\left\langle y-x, x^{*}\right\rangle \leq h(y), \forall y \in H\right\}, \quad \forall x \in H .
$$

Rockafellar [25] proved that $\partial h$ is a maximal monotone operator. It is easy to verify that $0 \in \partial h(v)$ if and only if $h(v)=\min _{x \in H} h(x)$. 
Theorem 4.5 Letf $: C \rightarrow C$ be a fixed $\kappa$-contraction. Let $h: H \rightarrow(-\infty,+\infty]$ be a proper convex lower semicontinuous function such that $(\partial h)^{-1}(0)$ is not empty. Let $\left\{r_{n}\right\}$ be a positive number sequence. Let $\left\{\alpha_{n}\right\},\left\{\beta_{n}\right\}$, and $\left\{\gamma_{n}\right\}$ be real number sequences in $(0,1)$. Let $\left\{x_{n}\right\}$ be a sequence generated in the following iterative process:

$$
x_{0} \in C, \quad x_{n+1}=\alpha_{n} f\left(x_{n}\right)+\beta_{n} \arg \min _{z \in H}\left\{h(z)+\frac{\left\|z-x_{n}-e_{n}\right\|^{2}}{2 r_{n}}\right\}+\gamma_{n} f_{n}, \quad \forall n \geq 0,
$$

where $\left\{e_{n}\right\}$ is a sequence in $H$ and $\left\{f_{n}\right\}$ is a bounded sequence in $C$. Assume that the sequences $\left\{\alpha_{n}\right\},\left\{\beta_{n}\right\},\left\{\gamma_{n}\right\},\left\{e_{n}\right\}$, and $\left\{r_{n}\right\}$ satisfy the following restrictions:

(1) $\alpha_{n}+\beta_{n}+\gamma_{n}=1$

(2) $\lim _{n \rightarrow \infty} \alpha_{n}=0, \sum_{n=0}^{\infty} \alpha_{n}=\infty$;

(3) $\sum_{n=1}^{\infty}\left|\beta_{n}-\beta_{n-1}\right|<\infty$;

(4) $\liminf _{n \rightarrow \infty} r_{n}>0, r_{n} \leq 2 \alpha, \sum_{n=1}^{\infty}\left|r_{n}-r_{n-1}\right|<\infty$;

(5) $\sum_{n=0}^{\infty}\left\|e_{n}\right\|<\infty, \sum_{n=0}^{\infty} \gamma_{n}<\infty$.

Then the sequence $\left\{x_{n}\right\}$ converges strongly to some minimizer of $h$.

Proof Since $h: H \rightarrow(-\infty, \infty]$ is a proper convex and lower semicontinuous function, we see that the subdifferential $\partial h$ of $h$ is maximal monotone. Putting $A=0$ and $y_{n}=J_{r_{n}}\left(x_{n}+\right.$ $e_{n}$ ), we see that

$$
y_{n}=\arg \min _{z \in H}\left\{h(z)+\frac{\left\|z-x_{n}-e_{n}\right\|^{2}}{2 r_{n}}\right\}
$$

is equivalent to

$$
0 \in \partial h\left(y_{n}\right)+\frac{1}{r_{n}}\left(y_{n}-x_{n}-e_{n}\right) .
$$

It follows that

$$
x_{n}+e_{n} \in y_{n}+r_{n} \partial h\left(y_{n}\right)
$$

By using Theorem 3.1, we draw the desired conclusion immediately.

\section{Competing interests}

The authors declare that they have no competing interests.

\section{Authors' contributions}

All authors contributed equally to this manuscript. All authors read and approved the final manuscript.

\section{Author details}

${ }^{1}$ Department of Mathematics, Hangzhou Normal University, Hangzhou, China. ${ }^{2}$ Department of Mathematics,

Gyeongsang National University, Jinju, Korea. ${ }^{3}$ College of Statistics and Mathematics, Yunnan University of Finance and Economics, Kunming, China.

\section{Acknowledgements}

The authors are grateful to the anonymous referees for useful suggestions, which improved the contents of the article. 


\section{References}

1. Combettes, PL, Wajs, VR: Single recovery by proximal forward-backward splitting. Multiscale Model. Simul. 4, 1168-1200 (2005)

2. Chen, GHG, Rockafellar, RT: Convergence rates in forward-backward splitting. SIAM J. Optim. 7, 421-444 (1997)

3. Rockafellar, RT: Monotone operators and the proximal point algorithm. SIAM J. Control Optim. 14, $877-898$ (1976)

4. He, RH: Coincidence theorem and existence theorems of solutions for a system of Ky Fan type minimax inequalities in FC-spaces. Adv. Fixed Point Theory 2, 47-57 (2012)

5. Peaceman, $\mathrm{DH}$, Rachford, $\mathrm{HH}$ : The numerical solutions of parabolic and elliptic differential equations. J. Soc. Ind. Appl. Math. 3, 28-41 (1955)

6. Cho, SY, Qin, X, Wang, L: Strong convergence of a splitting algorithm for treating monotone operators. Fixed Point Theory Appl. 2014, Article ID 94 (2014)

7. Moudafi, A, Thera, M: Finding a zero of the sum of two maximal monotone operators. J. Optim. Theory Appl. 94 425-448 (1997)

8. Bauschke, $\mathrm{HH}$ : A note on the paper by Eckstein and Svaiter on general projective splitting methods for sums of maximal monotone operators. SIAM J. Control Optim. 48, 2513-2515 (2009)

9. Tseng, P: Applications of a splitting algorithm to decomposition in convex programming and variational inequalities. SIAM J. Control Optim. 29, 119-138 (1991)

10. Tseng, P: A modified forward-backward splitting method for maximal monotone mappings. SIAM J. Control Optim. $38,431-446(2000)$

11. Cho, SY, Qin, X: On the strong convergence of an iterative process for asymptotically strict pseudocontractions and equilibrium problems. Appl. Math. Comput. 235, 430-438 (2014)

12. Lions, PL, Mercier, B: Splitting algorithms for the sum of two nonlinear operators. SIAM J. Numer. Anal. 16, 964-979 (1979)

13. Passty, GB: Ergodic convergence to a zero of the sum of monotone operators in Hilbert space. J. Math. Anal. Appl. 72 383-390 (1979)

14. Han, SP, Lou, G: A parallel algorithm for a class of convex programs. SIAM J. Control Optim. 26, 345-355 (1988)

15. Reich, S: Asymptotic behavior of contractions in Banach spaces. J. Math. Anal. Appl. 44, 57-70 (1973)

16. Kato, T: Nonlinear semigroups and evolution equations. J. Math. Soc. Jpn. 19, 508-520 (1967)

17. Xu, HK: Inequalities in Banach spaces with applications. Nonlinear Anal. 16, 1127-1138 (1991)

18. Aoyama, K, Kimura, Y, Takahashi, W, Toyoda, M: On a strongly nonexpansive sequence in Hilbert spaces. J. Nonlinear Convex Anal. 8, 471-489 (2007)

19. Barbu, V: Nonlinear Semigroups and Differential Equations in Banach Space. Noordhoff, Groningen (1976)

20. Liu, LS: Ishikawa and Mann iterative process with errors for nonlinear strongly accretive mappings in Banach spaces. J. Math. Anal. Appl. 194, 114-125 (1995)

21. Mitrinovic, DS: Analytic Inequalities. Springer, New York (1970)

22. Qin, $X$, Cho, SY, Wang, L: Iterative algorithms with errors for zero points of $m$-accretive operators. Fixed Point Theory Appl. 2013, Article ID 148 (2013)

23. Fan, K: A minimax inequality and applications. In: Shisha, O (ed.) Inequalities III, pp. 103-113. Academic Press, New York (1972)

24. Blum, E, Oettli, W: From optimization and variational inequalities to equilibriums problems. Math. Stud. 63, 123-145 (1994)

25. Rockafellar, RT: Monotone operators and the proximal point algorithm. SIAM J. Control Optim. 14, 877-898 (1976)

doi:10.1186/1687-1812-2014-166

Cite this article as: Qin et al.: Convergence of splitting algorithms for the sum of two accretive operators with

applications. Fixed Point Theory and Applications 2014 2014:166.

\section{Submit your manuscript to a SpringerOpen ${ }^{\circ}$ journal and benefit from:}

- Convenient online submission

Rigorous peer review

- Immediate publication on acceptance

- Open access: articles freely available online

- High visibility within the field

- Retaining the copyright to your article 